\title{
(1) essifserar \\ Chronic pancreatitis with Bochdalek hernia causing right-sided pleural effusion in a previously asymptomatic adult
}

\author{
Ho-Man Yeung, ${ }^{1}$ Erica Kumala, ${ }^{2}$ Steven Stanek, ${ }^{1}$ Xiaoying Deng ${ }^{1}$
}

'Department of Internal Medicine, Lewis Katz School of Medicine, Temple University, Philadelphia, Pennsylvania, USA ${ }^{2}$ Department of Family and Community Medicine, College of Medicine, University of Arizona, Tuson, Arizona, USA

Correspondence to Dr Xiaoying Deng, charlene6658@gmail.com

Accepted 1 May 2018

Check for updates

To cite: Yeung $\mathrm{H}-\mathrm{M}$, Kumala E, Stanek S, et al. BMJ Case Rep Published Online First: [please include Day Month Year]. doi:10.1136/bcr-2018224674

\section{SUMMARY}

A 41-year-old man with a medical history of chronic back pain, seizure disorder, alcohol and tobacco abuse presented with acute shortness of breath. Chest X-ray showed a large right-sided pleural effusion. Pleural fluid analysis was significant for an elevated amylase level, suggestive of pleural effusion secondary to pancreatitis. Magnetic resonance cholangiopancreatography (MRCP) revealed a persistent right-sided pleural effusion in connection with a right pararenal space fluid collection via a Bochdalek hernia. An endoscopic ultrasound found hyperechoic strands and foci, and pancreatic parenchyma consistent with chronic pancreatitis, as well as a pseudocyst in the pancreatic head. A chest tube was ultimately placed to continuously drain the pleural effusion. The patient was discharged and was referred to gastroenterology for outpatient follow-up. This case illustrates a rare presentation of chronic pancreatitis with a Bochdalek hernia as a right-sided pleural effusion in a patient who was previously asymptomatic.

\section{BACKGROUND}

Pleural effusions can occur from numerous aetiologies and are characterised as transudative or exudative in nature. Transudative effusions tend to occur in conditions that either decrease plasma oncotic pressure or increase capillary pressure (ie, congestive heart failure, cirrhosis, nephrotic kidney disease and pulmonary embolism). Exudative effusions typically occur from conditions that decrease the lymphatic flow from the pleural surface or increase the permeability of the pleura (ie, pneumonia, malignancy, pancreatitis, empyema and chylothorax). Chronic pancreatitis is an atypical cause of pleural effusions. Acute pancreatitis can commonly cause pleural effusions in up to $17 \%$ of patients; however, in chronic pancreatitis, pleural effusions are rarely seen. ${ }^{1-3}$ In particular, pancreaticopleural fistulas (PPFs) are seen in about $0.4 \%$ of patients who present with pancreatitis, and pseudocysts are found in 43\%-79\% of PPF cases. ${ }^{4-7}$

A Bochdalek hernia is a particular type of congenital PPF that occurs due to lack of appropriate fusion of the posterior foramina of the diaphragm during embryonic development, causing a hernia to occur where the pleuroperitoneal membrane does not form. ${ }^{8}$ This occurs in about 1 in 2500 births, is more common in males, and is usually diagnosed incidentally with chronic symptoms typically of abdominal pain and less commonly of dyspnoea or pulmonary disease. ${ }^{8}$ About $80 \%-90 \%$ of Bochdalek hernias are found on the left side because the right pleuroperitoneal canal usually closes earlier in development. ${ }^{3}$ There are currently fewer than 100 cases of Bochdalek hernia reported in adults in the literature, and only about 20 cases involving right-sided hernias, making this case a very unique presentation of pleural effusion secondary to chronic pancreatitis with a Bochdalek hernia.9

\section{CASE PRESENTATION}

A 41-year-old African-American man was admitted to the hospital after 2 days of acute onset of non-exertional shortness of breath and a non-productive cough. His medical history included chronic back pain and seizure disorder. He was involved in a motor vehicle accident about 2 months prior to admission, after which he started having the chronic back pain. He has an extensive history of alcohol use for at least 5 years, a seven pack-year history of tobacco use and marijuana use daily for the last 5 years. Vital sign was only remarkable for tachycardia with a heart rate $130 \mathrm{bpm}$ and tachypnoea. His blood pressure was $112 / 85 \mathrm{~mm} \mathrm{Hg}$, and he was breathing without supplemental oxygen with $97 \%$ $\mathrm{O}_{2}$ saturation. Physical examination on admission was significant for decreased breath sounds on the right compared with the left, diffuse wheezes, and rales on the right lower and mid lung fields. His cardiac examination was unremarkable, and his abdomen was soft and non-tender, with no costovertebral tenderness.

On admission, a chest X-ray was taken of the patient that showed a right pleural effusion extending through two-thirds of the patient's right hemithorax (figure 1). The patient also had a CT thorax with contrast that showed a right pleural effusion which appeared to communicate with right retroperitoneal fluid via a Bochdalek hernia as well as a $1.5 \mathrm{~cm}$ hypodensity in the posterior pancreatic body with dilation of the main pancreatic duct. CT of abdomen without contrast confirmed fluid in the right pararenal retroperitoneal space communicating with the large right pleural effusion via a right-sided Bochdalek hernia (figure 2). A cystic lesion in the posterior pancreatic body was also seen that appeared to communicate with the dilated main pancreatic duct with associated main pancreatic ductal dilatation. 


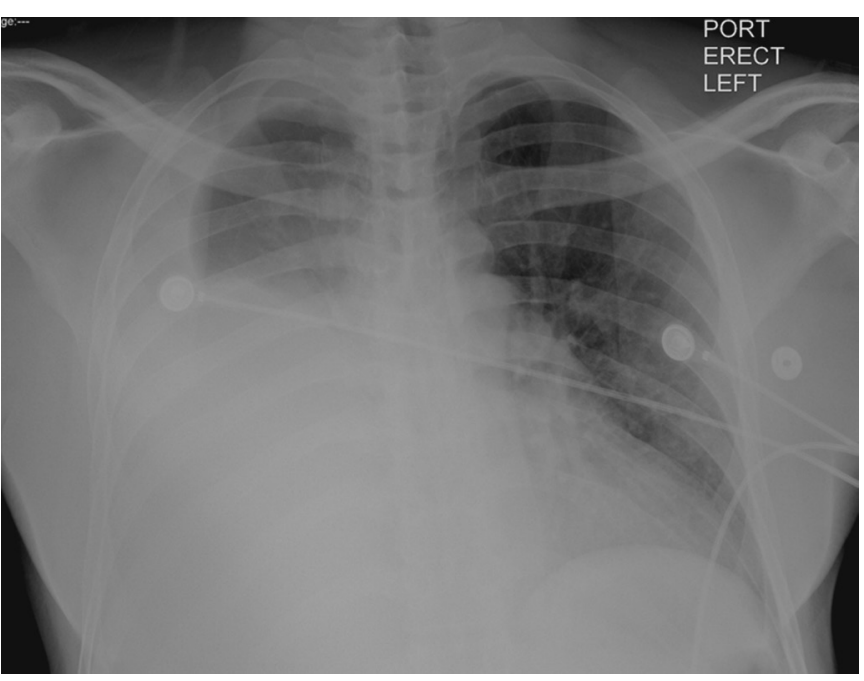

Figure 1 Chest X-ray on admission showing a large pleural effusion on the right.

A diagnostic and therapeutic thoracentesis was performed, removing a total of about $1.5 \mathrm{~L}$ of serosanguineous fluid. The pleural fluid was consistent with exudative effusion by Light's criteria, and was significant for elevated amylase level of 32 989 U/L. Cytology was negative for malignancy and showed mixed inflammatory cells. A repeat CT angiogram of the thorax was done after the thoracentesis which ruled out pulmonary embolus and suggested acute bronchopneumonia. It again demonstrated the persistent right-sided pleural effusion communicating with pararenal intra-abdominal collection via Bochdalek hernia and a $1.4 \mathrm{~cm}$ hypodense cystic lesion in the posterior pancreatic body. The patient was started on a 7-day course of antibiotics for his suspected bronchopneumonia.

Gastroenterology was consulted. In order to better elucidate the anatomy of his pancreas, an MRI of the abdomen with contrast was done which showed a lobulated pancreatic pseudocyst $(1.3 \times 0.6 \mathrm{~cm})$ in the uncinate process that appeared

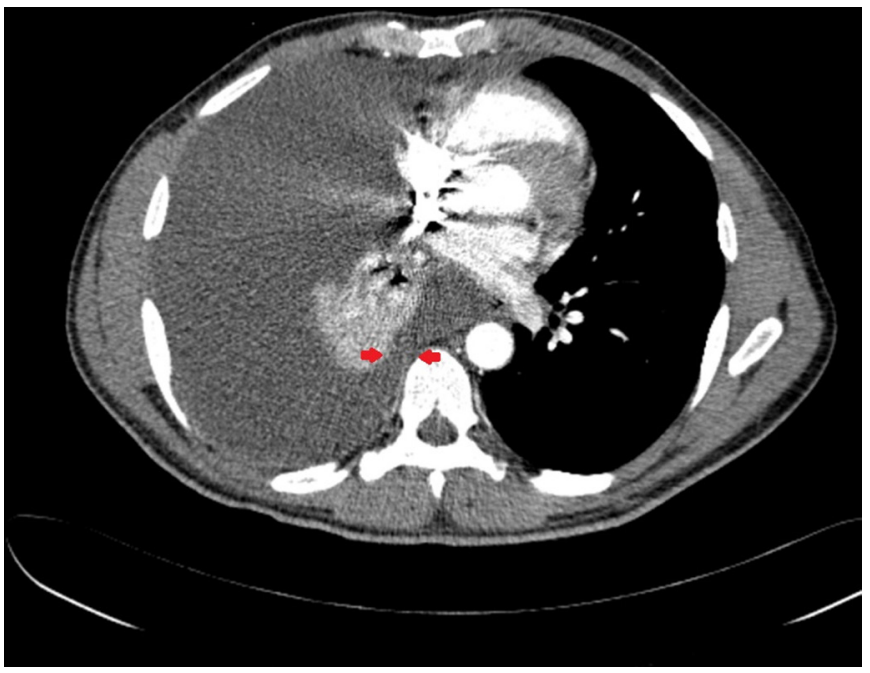

Figure $2 \mathrm{CT}$ abdomen without contrast demonstrating a Bochdalek hernia communicating with the right pleural effusion. Red arrows reveal fluid via Bochdalek hernia communicating with the right pleural effusion. to communicate with the main pancreatic duct and may be in continuity with the right posterior pararenal space collection. Another pseudocyst was found in the posterior pancreatic body measuring up to $1.4 \mathrm{~cm}$ in diameter. Endoscopic retrograde cholangiopancreatography (ERCP) and endoscopic ultrasound (EUS) with attempt for biopsy of the cystic mass were performed. The ERCP showed upstream dilatation of the main pancreatic duct with a stricture in the head for which a plastic stent was placed. The EUS showed pancreatic parenchymal abnormalities with diffuse echogenicity, hyperechoic strands and foci, lobularity and cysts all throughout the pancreas consistent with chronic pancreatitis possibly secondary to alcohol abuse and/or the patient's recent traumatic motor vehicle accident. A cystic lesion suggestive of a pseudocyst was also noted in the pancreatic head but tissue biopsy was unable to be obtained. These imaging findings suggest that the patient's right-sided pleural effusion was most likely secondary to chronic pancreatitis with Bochdalek hernia causing translocation of fluid from his right pararenal retroperitoneal space to his pleural space.

Since tissue samples of the mass were not obtained, tumour markers were checked in the patient's serum and pleural fluid to rule out malignancy. The patient had an elevated carcinoembryonic antigen(CEA) level in his serum $(79 \mathrm{U} / \mathrm{mL})$ and elevated CA 19-9 (4462 U/mL) and CA $125(1610 \mathrm{U} / \mathrm{ml})$ in the pleural fluid.

\section{DIFFERENTIAL DIAGNOSIS}

1. Pneumonia.

2. Empyema.

3. Malignancy.

4. Pancreatitis.

5. Chylothorax.

\section{TREATMENT}

The patient ultimately had a chest tube placed in his right lung in order to drain his pleural effusion. Over the course of 5 days, his effusion was drained through his chest tube, and repeat chest X-rays taken showed improvement of the effusion size (figure 3). The chest tube was clamped and then removed prior to discharge. The patient was recommended to follow-up with

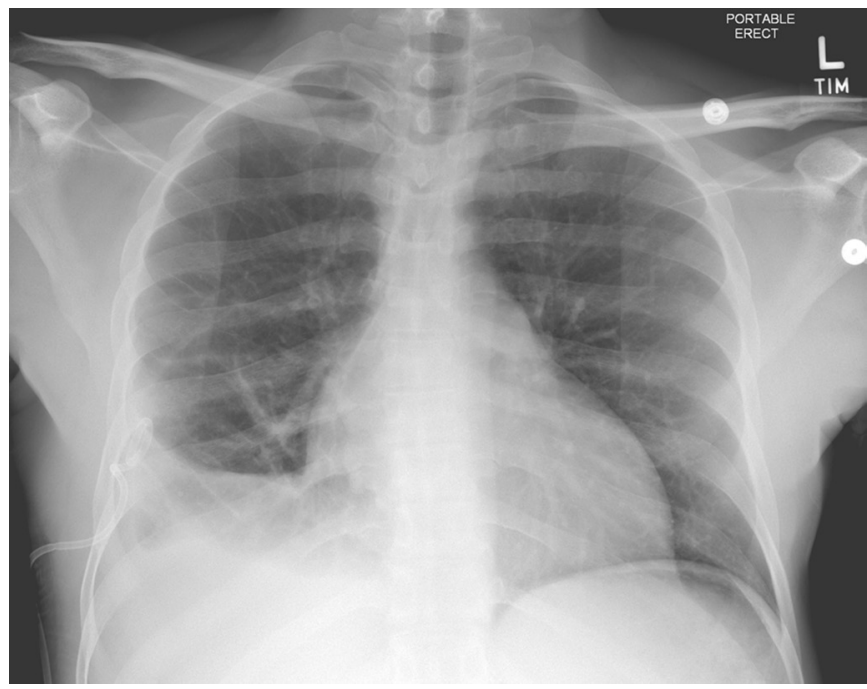

Figure 3 Chest X-ray prior to discharge showing decrease in effusion size. 
gastroenterology outpatient for a repeat CT chest in 4 weeks and a repeat ERCP in 6 weeks after discharge.

\section{OUTCOME AND FOLLOW-UP}

The patient was lost to follow-up after discharge. He never presented to any of his follow-up appointments that were made. Attempts to call the patient were made, but the phone number was non-functional.

\section{DISCUSSION}

The presentation of pleural effusions secondary to chronic pancreatitis with Bochdalek hernia is a rare finding. Bochdalek hernias occur as congenital anomalies and are often diagnosed via X-ray and CT scan as were done in this patient. ${ }^{9}$ A high amylase level in diagnostic thoracentesis should lead one to think more about chronic pancreatitis as a possible aetiology of a patient's pleural effusion. ${ }^{10}$ It is thought that the pancreatic digestive juices can travel posteriorly into the retroperitoneum and communicate through the fistula into the pleural space to form a pleural effusion rich in amylase. ${ }^{11} 12$ ERCP and MRCP are methods that can be used in order to better elucidate the anatomy of the pancreatic ducts in patients and possibly stent any areas that might have strictures. ${ }^{13}$ Bochdalek hernias are usually asymptomatic and only warrant interventions if they are causing significant symptoms or life-threatening conditions such as herniation of organs or malrotation. ${ }^{3}$ For our patient, his chest tube was able to successfully drain his effusion but he will need close outpatient follow-up to assess if the effusion reaccumulates and warrants further long-term or more invasive interventions. Treatment for Bochdalek hernias usually includes laparoscopic or thoracoscopic repair, ${ }^{3}$ with close postoperative monitoring for respiratory complications and pain management. ${ }^{13}$ Follow-up CT and ERCP may also further elucidate the connection of the

\section{Learning points}

- For patients with chronic pancreatitis presenting with acute onset of shortness of breath and pleural effusion, a Bochdalek hernia may be a possibility and should be considered in the differential diagnosis.

- Close monitoring for these patients are essential to prevent future symptoms and possible life-threatening complications associated with the hernia, as any fluid collection in the retroperitoneal space will communicate with the pleural space.

- Thoracentesis is essential to narrow down differential diagnosis for pleural effusions. patient's pseudocyst with the fistula and may warrant possibility for biopsy to exclude malignancy.

There have been cases previously reported of pleural effusions occurring secondary to PPF with associated pancreatitis, but these fistulas were often the result of acute rupture of the ductal anatomy or trauma rather than a congenital fistula. ${ }^{13}$ Our case report puts forth a rare presentation of chronic pancreatitis with a congenital fistula, namely a Bochdalek hernia, associated with a right-sided pleural effusion in a male patient who had no chronic symptoms who presented acutely with shortness of breath.

Contributors H-MY contributed to the writing, editing, formatting of the main manuscript and production of the figures. EK and SS contributed to the writing editing and formatting of the main manuscript. XD conceived the project and supervised the production of the manuscript. XD, H-MY, EK, SS certify that all authors have contributed and met criteria for authorship defined by BMJ.

Funding The authors have not declared a specific grant for this research from any funding agency in the public, commercial or not-for-profit sectors.

Competing interests None declared.

Patient consent Obtained.

Provenance and peer review Not commissioned; externally peer reviewed.

Open Access This is an Open Access article distributed in accordance with the Creative Commons Attribution Non Commercial (CC BY-NC 4.0) license, which permits others to distribute, remix, adapt, build upon this work non-commercially, and license their derivative works on different terms, provided the original work is properly cited and the use is non-commercial. See: http://creativecommons.org/ licenses/by-nc/4.0/

(C) BMJ Publishing Group Ltd (unless otherwise stated in the text of the article) 2018. All rights reserved. No commercial use is permitted unless otherwise expressly granted.

\section{REFERENCES}

1 Sut M, Gray R, Ramachandran M, et al. Pancreaticopleural fistula: a rare complication of ERCP-induced pancreatitis. Ulster Med J 2009;78:185-6.

2 Materne R, Vranckx P, Pauls C, et al. Pancreaticopleural fistula: diagnosis with magnetic resonance pancreatography. Chest 2000;117:912-4.

3 Laaksonen E, Silvasti S, Hakala T. Right-sided Bochdalek hernia in an adult: a case report. J Med Case Rep 2009:3:9291.

4 Fulcher AS, Capps GW, Turner MA. Thoracopancreatic fistula: clinical and imaging findings. J Comput Assist Tomogr 1999:23:181-7.

5 Safadi BY, Marks JM. Pancreatic-pleural fistula: the role of ERCP in diagnosis and treatment. Gastrointest Endosc 2000:51:213-5.

6 Oh YS, Edmundowicz SA, Jonnalagadda SS, et al. Pancreaticopleural fistula: report of two cases and review of the literature. Dig Dis Sci 2006;51:56-60.

7 Rockey DC, Cello JP. Pancreaticopleural fistula. Report of 7 patients and review of the literature. Medicine 1990;69:332-44.

8 Hamid KS, Rai SS, Rodriguez JA. Symptomatic Bochdalek hernia in an adult. JSLS 2010;14:279-81.

9 Rout S, Foo FJ, Hayden JD, et al. Right-sided Bochdalek hernia obstructing in an adult: case report and review of the literature. Hernia 2007;11:359-62.

10 Naha K, Dasari S, Vivek G, et al. Primary presentation of chronic calcific pancreatitis with massive unilateral pleural effusion. BMJ Case Rep 2013;2013:bcr2013009198.

11 Cameron JL, Kieffer RS, Anderson WJ, et al. Internal pancreatic fistulas: pancreatic ascites and pleural effusions. Ann Surg 1976:184:587-93.

12 Lipsett PA, Cameron JL. Internal pancreatic fistula. Am J Surg 1992;163:216-20.

13 Shah D, Desai AB, Salvi B. Pancreaticopleural fistula complicating chronic pancreatitis. BMJ Case Rep 2012;2012:bcr0320126038. 


\section{Unusual association of diseases/symptoms}

Copyright 2018 BMJ Publishing Group. All rights reserved. For permission to reuse any of this content visit http://group.bmj.com/group/rights-licensing/permissions.

BMJ Case Report Fellows may re-use this article for personal use and teaching without any further permission.

Become a Fellow of BMJ Case Reports today and you can:

- Submit as many cases as you like

- Enjoy fast sympathetic peer review and rapid publication of accepted articles

Access all the published articles

- Re-use any of the published material for personal use and teaching without further permission

For information on Institutional Fellowships contact consortiasales@bmjgroup.com

Visit casereports.bmj.com for more articles like this and to become a Fellow 